\title{
O NASCIMENTO PSICOLÓGICO
}

\section{Elaine Pedreira Rabinovich ${ }^{1}$}

RABINOVICH, E. P. O Nascimento Psicológico. R. B. C. D. H. 1(1): São Paulo, 1991.

\section{RESUMO}

A autora conceitna o nascimento psicológico como a separação entre criança e mãe; após uma fase em que ocorreu um estado de fusão entre ambas.

Essa separação ocorre através de um processo em que, de um lado, o bebe encontra satisfação de suas necessidades através da maternagem, enquanto, de outro, vai sendo exposto a um processo de frustração que o leva a recriar, através da representação mental, o objeto do qual depende para sobreviver.

É descrito, de um modo geral, esse processo, enfatizando-se a interrelacão mãe-criança.

\section{INTRODUÇÃO}

Da mesma forma que o nascimento biológico é marcado por uma separação física, o nascimento psicológico é uma separação psíquica entre mãe e criança. É o que o desmarne, em última instância, significa. Até então, a criança não nasceu no sentido de que não se diferenciou da mãe. Haveria, até ar, um estado de simbiose entre esses dois seres. A característica essencial da simbiose é a fusão somatopsíquica onipotente, alucinatória ou delirante com a representação da rrãe, ou seja, o delírio de uma fronteira comum (Mahler, 1977, p. 63).

A primeira separação entre mãe e criança se dá entre seis e nove meses. E o momento em que a criança diferencia o eu do não-eu. A criança não percebe quem ela é, mas que ela é.

A individuação é o processo através do qual ela perceberá quem ela é; para alguns autores, como Mahler (1977, p. 146), esse processo inicia-se aos 30 meses e concretiza-se, para Yung (1960, p. 525), em torno dos 35 anos. Entre esses dois marcos há vários outros momentos de sepa- ração-individuação, como a adolescência, onde a emergência de papéis sexuais e sociais ocasiona novas separações dos pais e crises quanto à questão da identidade. Tanto a separação quanto a individuação podem ser descritas como diferentes modos de organização do ego e de sua relação com o meio.*

Outras áreas de conhecimento têm trazido aportes significativos para uma compreensão ampliada do porque o nascimento psicológico ocorre fora do útero.

Gould (1987, p. 66), um evolucionista neodarwiniano, por exemplo, propõe que os bebés humanos nascem como embriões c como embriões permanecem durante os primeiros nove meses de vida. Segundo este autor: "se as mulheres dessem à luz quando 'deviam' - depois de uma gestação de cerca de um ano e meio- nossos bebes teriam as mesmas características precoces de outros prirnatas". Estas características se referem ao tamanho do cérebro, à calcificação e a níveis globais de desenvolvimento comparados aos dos primatas. O próprio crescimento físico do bebe acompanharia o padrão de crescimento dos fetos

Psicóloga clínica e pesqoisadora do CDN.

* O termo “ego” está sendo utilizado para designar o marxismo psíquico resposável pela adaptação do indivíduo ao meio. A definição de ego utilizada pela autora é o resultado da somatória de conceitos de vários autores. 
de primatas e mamíferos e não os de filhotes de primatas. Além disso, ao nascer, o cérebro de um bebe humano tem apenas um quarto de seu tamanho final. Para a maioria dos mamíferos, contudo, o crescimento do cérebro é um fenómeno exclusivo da fase fetal. Gould (1987, p. 70) propõe ser esse o motivo do nascimento "antecipado" dos bebés humanos; dado 0 desenvolvimento do cérebro humano, um quarto de seu tamanho é o máximo que este pode ter para poder passar pelo canal pélvico. Foi por causa disso, pensa o autor, que "a gestação do ser humano precisou ser encurtada em relação ao seu desenvolvimento".

Complementando essas considerações, sabe-se que os tecidos nervoso e muscular se desenvolvem fora do altero ate os 30 meses. Piaget (1967, p. 29), para explicar os vários estágios da inteligência, valeu-se de um constructo hipotético: os créodos, que seriam caminhos para o crescimento intelectual que, existindo em potencial, se atualizariam na intersecção sujeito-ambiente. As glias são conceitos neurológicos, fornecendo a mesma base orgânica para os achados psicológicos. Aos 6-8 meses, o processo de mielinização garante o suporte somático para os ganhos adquiridos em nivel psíquico, sendo, na verdade, dois lados de uma mesma moeda.

Eis porque o nascimento psicológico também ocorre fora do útero. Nessa mesma medida, ele se dá no processo da interação social.

Dentro dessa perspectiva, pode-se entender toda a amplitude da afirmação de Winnicott (1982, p. 43): “o potencial herdado por um bebé só pode vir a ser um bebe se ligado à maternagem; sempre que encontramos um bebé, encontramos a maternagem". "Mãe” designa, para nós, a pessoa ou pessoas que cuidam da criança de um modo contínuo e sistemático. A maternagem, o sistema de cuidados mãe-criança, é o protótipo de todos os relacionamentos sociais e, ao mesmo tempo, a semente do individuo. A mãe acumula, assim, sua própria individualidade, sua história pessoal, a estrutura e o funcionamento familiar, a classe social a que pertence, seu grupo cultural e, em círculos cada vez mais abrangentes, a história de toda a humanidade. Para Spitz (1983, p. 31), é essa pessoa que transmite à criança o universo onde ela está inserida.

O fala de a criança não nascer pronta, como em outras espécies, torna a humanização possível. Trata-se de um longo período de irrpnn ing, possível porque mãe e criança, partindo de um estado de fusão, lentamente vão construindo de um lado, para destruir de outro, essa relação absorvente-absorvida e dar origem a dois seres separados que o corte do cordão umbilical apenas simbolizara.
O nascimento psicológico é o produto de uma relação e o fruto de uma conquista. Há um inter-relacionamento onde dois seres estão interferindo e modificando-se mutuamente: o filho faz a mãe tanto quanto esta o faz, embora em níveis e versões muito diferentes.

O que falta à criança é compensado e fornecido pela mãe. A mãe coloca-se como uma espécie de "ego exterior", protegendo, cuidando, reconhecendo e expressando necessidades. A medida que a relação evolui, a mãe vai recuando nessa sua atividade e fornecendo os elementos para que a criança adquira sua autonomia. Esta é uma conquista da criança que tem de superar frustrações para se organizar no nível imediatamente superior. Portanto, a separação e a individuação são frutos da atividade da criança na sua interação com o mundo.

No início, o recém-nascido não percebe a mãe como distinta de si próprio; ela é simplesmente parte da totalidade de suas necessidades e satisfação. A criança apenas registro o alívio da tensão e não o objeto que causa o alívio. Atribui o alivio a si próprio, e isso é o que chamamos de onipotência. Ao nascer, o bebe é parcialmente protegido por uma barreira aos estímulos que, por assim dizer, perpetua, na vida extra-uterina, condições intrauterinas. Grande parte da percepção passa pelos sistemas proprioceptivos e interoceptivos. As reações da criança ocorrem principalmente a partir da percepção de necessidades comunicados por esses sistemas. Com o amadurecimento do sistema nervoso e as sucessivas exposições a situações parecidas, vão-se imprimindo alguns circuitos nervosos, além dos aios reflexos presentes no nascimento. Este sistema dá origem a padrões de ação na forma de traços mnemónicos. As situações que se repetem, e que dão origem a essas impressões, são principalmente aquelas às quais a mae dá significado, tais como fome-seio, frio-agasalho. É a mãe quem, através de suas representações, dá nome às necessidades da criança e com isso estabelece relações fora, que passam a estar dentro da criança.

A base das reações do recém-nascido é constituída por aios reflexos sobre os quais se montam cadeias simples de ações e, depois, cada vez mais complexas, até que um conjunto dessas ações se torne independente e forme um núcleo gerador de novas sínteses. Esses núcleos são a origem do ego; quando vários núcleos se unem há um ego rudimentar.

Segundo Hoffer (1983, p. 20), o conceito “boca-eu” ’é a primeira organização do eu e a mão é o agente desta organização. Não é necessário lembrar o espaço ocupado pela mão e pela boca na representação do homúnculo no córtex cere- 
bral. A cavidade oral é o grande depositário das sensações do recém-nascido com total presença de sensações interoceptivas e proprioceptivas. Quando o bebe mama, ele olha a mãe, caracterizando, assim, o que Spitz (1983, p. 78) descreveu como a "experiência situacional unificada", ou seja, a conexão mão-boca-labirinto-pele funde-se com a primeira imagem facial, a face da mãe. Com esse olhar, inicia-se a transição da percepção por contato para a percepção à distância. A percepção à distância, segundo Spitz (1983, p. 79), é a utilizada pelo adulto; é o que ele chama de sistema diabético baseado no Sistema Nervoso Central, musculatura estriada e localização precisa dos órgãos sensoriais. A experiência da amamentação ativa o sistema perceptual diacrítico que gradualmente substitui a organização cinestésica original e primitiva. Esta organização, por sua vez, consiste em sensações globais difusas, sincréticas e viscerais, envolvendo a musculatura lisa e o sistema nervoso simpático-parassimpático. Esta mudança de sistema é que permite a percepção do mundo, existindo fora da criança.

Como último elemento nesta experiência situacional unificada, a mãe olha a criança. O olhar da mãe fomece, por assim dizer, a própria imagem da criança. Winnicott (1975, p. 154) diz que o precursor do espelho é o rosto da mãe e que o bebé vê a si próprio no rosto da mãe. Se não houver retomo, haverá atrofia da capacidade criativa e/ou retirada para si próprio. Assim, é o olhar da mãe a via para a mudança do sistema perceptual cenestésico para o sistema perceptual diacrftico. Não apenas o olhar da mãe fornece esse caminho: o talo, o modo de pegar e segurar, o tom e o ritmo de sua voz, o calor de seu corpo, o seu movimento. Baseada nessas trocas recíprocas entre criança e mãe, fom^la-se a imagem corporal da criança, sendo esta a base sobre a qual é construído o eu da criança.

Segundo Mahler (1977, p. 71), quando nasce, a criança está protegida por um escudo autístico. Os cuidados matemos diminuem a tensão, assim como os comportamentos expulsivos de tossir, urinar, espirrar, defecar, regurgitar e vomitar. A criança não diferencia, mas discrimina diferentes qualidades de experiência: uma boa/ prazeiroza, outra má/desprazeirosa. A mãe é todo o prazer e todo o desprazer, ela é tanto a fome, quanto a sua satisfação. A partir do segundo mês o bebe começa a ter uma consciência difusa de que algo o satisfaz. O escudo começa a se tompor e há um deslocamento da catexia, da energia libidinal para a órbita sirnbiótica da unidade dual. O escudo é substituido pela simbiose. Qualquer experiência desprazeirosa, exterior ou interior, é projetada para além da fronteira comum. Isso pro- tege o ego rudimentar e possibilita o início da identificação do objeto externo. Aos três meses, o sorriso social inespecífco, caracterizado pela resposta do bebe ao sinal gestáltico "rosto em movimento" marca a entrada da criança no estágio de relação de objeto que satisfaz a necessidade, isto é, a criança começa a perceber que a só tisfação de suas necessidades vem de um objeto parcial que teria como função satifazê la A resposta do sorriso especifico dirigido à mãe é um sinal crucial de que um elo particular entre criança e mãe foi estabelecido. O próximo sinal é o "desabrochamento", um estado de alerta bem mais permanente, mais persistente e com direcionarne ${ }^{\wedge}$ nto de objetivos, isto indica que a atenção do beba, que durante os primeiros meses de simbiose era, em grande parte, dirigida para dentro, gradualmente se expande através do surgimento da atividade perceptiva dirigida para fora durante os crescentes perfodos de vigília.

Aos seis meses tem início uma experiência de tentativa de separação-individuação. Podese observar comportamentos da criança como: puxar o cabelo, as Grelhas, o nariz da mãe; tentar colocar comida na boca da mãe; afastar o corpo dela quando no seu colo, de modo a poder olhá-la melhor, examinando-a e ao mundo ao seu redor. Estes comportamentos são sinais definidos de que o bebe começa a diferenciar seu próprio corpo do corpo da mãe.

No sexto e sétimo mês tem lugar o auge da exploração táctil, manual e visual do rosto da mãe pelo bebé, assim como das partescobertas e descobertas do seu corpo. O beba dá seus primeiros passas em direção à libertação num sentido corporal, de sua condição completamente passiva de bebé de colo. Ocorreria então, para alguns autores, como Spitz (1983, p. 141), a ansiedade dos oito meses: quando um estranho se aproxima da criança, ela apresenta intensidades variaveis de apreensão ou ansiedade e rejeita 0 estranho. Nesse momento a criança distingue claramente um estranho de um não-estranho. Para Spitz (1983, p. 145), a ansiedade manifestada pela criança estaria ligada ao medo de perda da mãe: quando confrontada com um estranho, sua reação é de que nao se trata de sua mae e, portanto, esta abandonou-a Ainda segundo Spitz, assim como para outros autores, a ansiedade dos oito meses reflete o falo de que a criança estabeleceu, neste momento, uma verdadeira relação objetal, isto é, de que a mãe total se tornou seu objeto de amor, e a própria criança se diferenciou da mae.

Mahler discorda de Spitz quanto ao comportamento que indicaria o momento da constituição da verdadeira relação objetal. Para ela (1977, p. 78), o padrão visual de "confrontar com 
a mãe” a partir dos sete a oito meses é o sinal mais importante e razoavelmente regular do início da diferenciação somato-psíquica. Segundo ela, confrontar é comparar o familiar com o nãofamiliar, comparar a mãe e o outro e descobrir o que pertence ou não ao corpo da mãe. Uma expectativa confiante, fruto da relação da criança com o seu meio, garantiria ou não esta exploração e esta comparação, com ou sem ansiedade.

Segundo Mahler (1977), o nascimento da criança como indivíduo começa quando, numa reação à resposta seletiva da mãe e suas “deixas”, a criança gradualmente altera seu comportamento. Segundo essa autora, seria a necessidade inconsciente específica da mãe que ativa, entre as potencialidades infinitas do bebe, aquelas que, em particular, criam, para cada mãe, a criança que repetiria suas próprias necessidades individuais e singulares, dentro dos limites dos dons inatos da criança.

É a tessitura do relacionamento mãe-criança que permite que de um estado de não-diferenciação o bebe vá acumulando experiências, registrando-as, organizando-as, integrando-as e, no final deste processo, tenha condições de perceber a mãe como alguém diverso dele e ele próprio como separado dela.

O que a mãe reflete é usualmente chamado de “amor”. Através da identificação primária, a criança vai incorporando as técnicas de cuidado até conseguir cuidar de si própria: seria o "amor-próprio".

Para que experiências sejam imprimidas, é preciso que elas tenham u n significado, o material não significativo não é registrado. Grande parte do significado das experiências é dado através de trocas com outro ser humano. Só uma relação recíproca ou "reciprocante” é capaz disto. $\mathrm{O}$ abeto materno orienta os afetos do bebe e confere qualidade de vida à experiência deste. É no (por e do interesse da mãe e da criança por esta) inter-essere (= entre seres) que a criança nasce, aparece e vem ocupar o seu lugar no mundo.

A atitude emocional materna, facilitadora ou controladora, permissiva ou limitadora, aprovadora ou rejeitadora, positiva ou negativa, é que vai ajudar a desenvolver tais ou quais relações. Além disso, há um feed-back recíproco e constante dentro da díade: trata-se de uma relação complementar, homeostática, embora de dois seres tão diferentes. Enquanto a mãe satisfaz as necessidades do bebe, esse satisfaz ou não as da mãe. Apenas para ilus trar a complexidade dessa inter-relação complementar, citamos a necessidade do bebe de mamar para aliviar a tensão que a mãe sente quando está com os selos entumescidos.

Sob condições sub-humanas de vida a mãe não conseguirá humanizar o filho. Condições sacio econôrnicas muito precárias, impedindo que a mãe se perceba e se constitua como um indivíduo, determinam condições de subnutrição afetiva para o Slho. As condições sócio-econômicas são a totalidade e os invariantes dentro dos quais a criança nasce e em função do que se estrutura a díadre mãe-criança. As condições sócioconômicas são as necessárias, mas não suficientes para a inserção da mãe de e para a sociedade e da criança, de e para a mãe. Já as condições culturais poderiam ser as suficientes, embora não necessárias, para que o desenvolvimento ocorra de tal ou qual modo.

Por “mãe” tem sido designado a(s) pessoa(s) que satisfaz(em) as necessidades da criança, que cuida(m) dela de um modo sistemático e continuo, que lhe dá proteção, conforto e assistência e que tem um relacionamento reciprocante com ela. A maternagem não se refere necessariamente à mãe natural, embora frequentemente seja por ela realizada. Crianças criadas em creches ou com outros tipos de vinculações, que não com a mãe, desenvolver-se-ão de acordo com a qualidade destas vinculações. Consideramos características essenciais da maternagem a continência ou holding, a reciprocidade afetiva e comunicativa, e os cuidados contínuos e sistemáticos. O conceito de maternagem nos parece suficientemente amplo para englobar sistemas de cuidados que, embora diversos entre si, garantam a sobrevivência dos bebés como seres humanos, adaptados à cultura onde viverão e capazes de transmiti-la aos seus descendentes.

Enquanto a "gestação psicológica” é fruto da presença materna, o “parto psicológico” é fruto da ausência da mãe. O nascimento psicológico ocorre porque, entre a sensação de necessidade e o seu desaparecimento através da satisfação, há demoras. Estás demoras—a falta-desempenham um papel fundamental no desenvolvimento adaptativo. A percepção do ambiente baseia-se na tensão gerada por um impulso não satisfeito.

Freud já dizia que uma condição para que se faça 0 teste da realidade é que os objetos que uma vez trouxeram real satisfação tenham sido perdidos. Winnicott (1975, p. 25) continua que não há possibilidade alguma de um bebe progredir do princípio do prazer para o princípio da realidade a menos que exista uma "mãe suficientemente boa”. Esta é uma mãe que efetua uma adaptação ativa às necessidades do bebe, uma adaptação que diminui gradativamente a intervenção materna, segundo a crescente capacidade da criança em aquilatar o fracasso da adaptação e em tolerar os resultados da frustração. Inicialmente, a mãe propicia a ilusão de que o seio, ou seja, todos os cuidados fazem parte do bebê. A mãe coloca o seio real exatamente onde e quando o 
bebê está pronto para criá-lo. Assim procedendo, cria uma área intermediária entre o que é objetivamente percebido e o que é subjetivamente concebido, entre a realidade e a criatividade. A mãe sobrepõe a realidade ao desejo da criança e dá a essa a ilusão de que existe uma realidade externa correspondente à sua própria capacidade de criar. Após isto, a mãe tem a tarefa de desiludir gradativamente. Se a ilusão-desilusão correr normalmente, está pronto o palco para a frustração do desmame, isto é, a separação da figura materna e o início da constituição do bebé enquanto indivíduo (Winnicott, 1975, p. 28).

O objeto real ausente - a mãe - frustra. A frustração é sentida como aniquilamento. Para diminuir a dor, para se apaziguar, a criança elabora e coordena os registros espalhados no sistema nervoso. É a angústia ante a ausência da mãe que faz com que a criança a recrie em sua mente, represente-a mentalmente mesmo em sua ausência. Com isto, adquire a noção de permanência do objeto. A mãe, tornada permanente e não mais produto de sua onipotência, faz com que a criança reconheça que seus sentimentos de ódio, quando ela a frustra, e os de amor, quando ela a gratifica em suas necessidades, são dirigidos a uma mesma pessoa. Concomitantemente, a própria criança se reconhece como sujeito desses dois sentimentos, fundindo impulsos agressivos e libidinosos. A partir deste momento, a criança passa a se preocupar com a mãe como um todo.

A tolerância à ambiguidade e à frustração é a condição para o início de operações mentais de complexidade cada vez maior. O intelecto, ele próprio, é um produto da falta e a cultura e a civilização, suas conseqüências. Tudo que nos foi dado uma vez e que nos falta tentamos criar na realidade a fim de obtermos a segurança que a entrada no mundo nos tirou. Por ironia dos deuses, a perda da onipotência é o momento do nosso surgimento como seres humanos.

\section{BIBLIOGRAFIA}

GOULD, S. Darwin e os Grandes Enigmas da Vida. São Paulo, Martins Fontes, 1987, pp. 6570.

HOFFER, W. O Desenvolvimento Prirnitivo e a Educação da Criança. Rio de Janeiro, Imago, 1983, pp. 19-27.

MAHLER, M. S. O Nascimento Psicológico da Crianca: Simbiose e Individuacão. Rio de Janeiro, Zahar, 1977, pp. 59-86.

PLAGET, J. Biologie et Connaissance. Paris, Gallinard, 1967

SPITZ, R. A. O Primeiro Ano de Vida. São Paulo, Martins Fontes, 1983, pp. 23-164.

WINNICOTT, D. W. Da Pediatria à Psicanálise. Rio de Janeiro Francisco Alves, 1982, p. 43. O Brincar e a Realidade. Rio de Janeiro, lmago,

YTJNG, C. G. Tipos Psicológicos. Rio de Janeiro, Zahar, 1976, pp. 525-527. 